\title{
Influence of Honey Bee, Apis mellifera, Hives and Field Size on Foraging Activity of Native Bee Species in Pumpkin Fields
}

\author{
DEREK R. ARTZ ${ }^{1}$ CYNTHIA L. HSU, aND BRIAN A. NAULT
}

Department of Entomology, Cornell University, New York State Agricultural Experiment Station, 630 W. North Street, Geneva, New York

\begin{abstract}
Environ. Entomol. 40(5): 1144-1158 (2011); DOI: http://dx.doi.org/10.1603/EN10218
ABSTRACT The purpose of this study was to identify bee species active in pumpkin fields in New York and to estimate their potential as pollinators by examining their foraging activity. In addition, we examined whether foraging activity was affected by either the addition of hives of the honey bee, Apis mellifera L., or by field size. Thirty-five pumpkin (Cucurbita spp.) fields ranging from 0.6 to 26.3 ha, 12 supplemented with A. mellifera hives and 23 not supplemented, were sampled during peak flowering over three successive weeks in 2008 and 2009. Flowers from 300 plants per field were visually sampled for bees on each sampling date. A. mellifera, Bombus impatiens Cresson, and Peponapis pruinosa (Say) accounted for $99 \%$ of all bee visits to flowers. A. mellifera and B. impatiens visited significantly more pistillate flowers than would be expected by chance, whereas $P$. pruinosa showed no preference for visiting pistillate flowers. There were significantly more A. mellifera visits per flower in fields supplemented with A. mellifera hives than in fields not supplemented, but there were significantly fewer $P$. pruinosa visits in supplemented fields. The number of $B$. impatiens visits was not affected by supplementation, but was affected by number of flowers per field. A. mellifera and P. pruinosa visits were not affected by field size, but $B$. impatiens visited fewer flowers as field size increased in fields that were not supplemented with A. mellifera hives. Declining A. mellifera populations may increase the relative importance of $B$. impatiens in pollinating pumpkins in New York.
\end{abstract}

KEY WORDS Bombus impatiens, Peponapis pruinosa, pollination, Cucurbita spp.

Pollinators provide an essential ecosystem service that is important to both natural and agricultural systems, providing as much as 200 billion dollars in pollination services worldwide (Klein et al. 2007, Kremen et al. 2007, Aizen et al. 2009, Gallai et al. 2009). Many insectpollinated crops rely on both native bee species and the introduced honey bee, Apis mellifera L., for pollination (Klein et al. 2007, James and Pitts-Singer 2008), and both natural and agroecosystems experience spatial and temporal variation in the diversity and abundance of pollinators that visit flowers for nectar and pollen (Gomez and Zamora 1999, Petanidou et al. 2008, Brunet 2009, Artz et al. 2010).

In areas of high commercial agricultural production, managed A. mellifera are particularly important pollinators because of their ability to pollinate many different crops and because their colonies are large and relatively easy to transport. Many growers rely on managed A. mellifera as the sole bee species to provide the majority of pollination services, particularly for crops with high pollination requirements (Free 1993, Delaplane and Mayer 2000). The economic value attributed to A. mellifera for crop pollination in the

${ }^{1}$ Corresponding author, e-mail: dra54@cornell.edu.
United States is estimated to be 14.6 billion dollars annually (Morse and Calderone 2000).

Native bee species also play a major role in pollinating commercial crops. In California's Central Valley, Kremen et al. (2002a,b) reported 30 native bee species, mostly solitary bees, visiting watermelon [Citrullus lanatus (Thunb.) Matsum. \& Nakai] flowers. In the mid-Atlantic United States, Shuler et al. (2005) assessed the abundance and assemblage of pollinators visiting pumpkin and squash (Cucurbita spp.) and found that the squash bee, Peponapis pruinosa (Say), a native, solitary ground-nesting species, was the most abundant pollinator on 15 of the 25 farms; A. mellifera and bumble bees, Bombus spp., were the other most abundant pollinators visiting pumpkin and squash flowers in that study. Also in the mid-Atlantic United States, Winfree et al. (2007) documented 46 bee species visiting watermelon flowers in 23 small fields $(<1$ ha), and Julier and Roulston (2009) reported a diverse bee community visiting pumpkin flowers in varioussized fields. In these studies, native pollinators visited flowers frequently enough to maximize fruit yield. Native bees provide pollination services to a variety of crops in the United States with an estimated economic value of 3.07 billion dollars annually (Losey and Vaughan 2006), and their role in pollinating agricul- 
tural crops may become even more important if $A$. mellifera populations continue to decline (NRC 2006, vanEngelsdorp et al. 2011).

Pumpkin production in New York ranks high nationally with an annual value that averages approximately 38 million dollars (USDA-NASS 2008). Pumpkin is a cucurbit crop, Cucurbita spp., with high pollination demands requiring insect vectors to transfer pollen from staminate flowers to pistillate flowers (Hurd et al. 1974, Kevan et al. 1988). Previous pollination studies in the mid-Atlantic United States identified a number of bee species visiting pumpkin flowers including A. mellifera, Bombus spp., P. pruinosa, Melissodes bimaculata Lepeletier (Apidae), and several halictid bees, Lasioglossum spp., Agapostemon spp., and Halictus spp. (Halictidae) (Fronk and Slater 1956, Willis and Kevan 1995, Shuler et al. 2005, Julier and Roulston 2009). Pumpkin flowers are also visited by various other non-Apoid insects such as striped cucumber beetles, Acalymma vittatum (F.), and spotted cucumber beetles, Diabrotica undecimpunctata howardii Barber, both major herbivores of pumpkins and vectors of the bacterial wilt pathogen, Erwinia tracheiphila (Smith) (Metcalf and Lampman 1989, Metcalf et al. 1995). Despite their frequent visitation to flowers, cucumber beetles (Coleoptera: Chrysomelidae) are not important pollinators because they carry small amounts of pollen (Andersen and Metcalf 1987; D.R.A., personal observation). The most common native insect pollinators of pumpkin in New York are not well known.

The importance of a bee species as a pollinator of a particular crop is somewhat dependent on foraging behavior (Ne'eman et al. 2006, James and Pitts-Singer 2008). For example, in Utah, Tepedino (1981) found that $P$. pruinosa preferred summer squash staminate flowers over pistillate ones, whereas A. mellifera visited more pistillate flowers than staminate ones. These results suggested that A. mellifera foragers were preferentially foraging for nectar resources from pistillate flowers. These findings highlighted how different bee species may favor one flower type over another during foraging, and that these pollinator preferences and discrimination abilities may influence plant reproductive success. Highly preferred pistillate flowers presumably would receive more visits, thus increasing the probability of pollen deposition and pollination success (Galen 1989, Meléndez-Ackerman and Campbell 1998). Preference for visiting staminate or pistillate flowers in pumpkin fields is not known for the most common pollinator species in New York.

The abundance of a particular pollinator in a crop during bloom, measured by visitation frequency to crop flowers, may also provide insight into the relative importance of a species as a pollinator. Some bee species may exclusively visit pumpkin flowers and may be abundant throughout the growing season, whereas others may visit pumpkin flowers only when other floral-rich resources are not available, potentially resulting in fewer visits to pumpkin flowers (Eickwort and Ginsberg 1980, Keasar et al. 2002). In New York, pumpkin growers can rent A. mellifera hives to try and increase pollination success and yield in their fields, although many growers believe that the activity of native pollinators and feral A. mellifera is sufficiently high to provide adequate pollination of their pumpkin crops. Past studies have shown that native pollinators visit flowers frequently enough to provide sufficient pollination services for cucurbit crops grown in small fields ( $<1 \mathrm{ha}$ ) (Winfree et al. 2007), but this trend is not known for larger fields ( $>1$ ha), which are typical in New York. The relative activity of A. mellifera and native bee species in pumpkin fields supplemented and not supplemented with A. mellifera hives and the effect of field size on flower visits by A. mellifera and native bee species have not been studied in New York.

The principal objectives of this study were to: 1) identify and estimate the relative number of visits for bee species that visit pumpkin flowers in commercial fields in New York, 2) compare the number of flower visits to staminate and pistillate pumpkin flowers for the most common bee species, 3) test whether the number of flower visits by A. mellifera and native bee species differs between fields supplemented or not supplemented with A. mellifera hives, and 4) describe the impact that field size has on flower visits by the most common bee species. We do not provide quantitative data on how bee visits relate to fruit yield (see Artz and Nault 2011); rather, we identify the most common bee species and discuss the implications of their foraging activity on pollination services in pumpkin fields.

\section{Materials and Methods}

Study System. Pumpkins are annual plants that have been cultivated in the Americas for their nutritious seeds and fruit since the beginning of plant domestication and agricultural development (Whitaker and Davis 1962, Nee 1990). All four of the main domesticated pumpkin species, Cucurbita pepo L., C. argyrosperma Huber (=C. mixta Pang.), C. maxima Duch., and C. moschata (Duch. ex Poir.) originated in either North or South America (Whitaker and Bird 1949, Whitaker 1981, Decker 1988). Pumpkins are monoecious plants, bearing separate staminate and pistillate flowers on the same plant, but staminate flowers generally outnumber pistillate flowers (range, $0 ; \% ; 5: 1-$ 11:1) (Whitaker 1931, Nepi and Pacini 1993, Delaplane and Mayer 2000). Plants produce large flowers that last one day, typically opening at dawn and closing by late morning or early afternoon (Tepedino 1981; D.R.A., unpublished data). Staminate flowers are typically produced first in the season and provide both nectar and pollen, whereas pistillate flowers open later and only offer nectar as a reward for foraging insects (Free 1993, Delaplane and Mayer 2000). In New York, pumpkins are planted from late May to early July and flowers are produced from July to early September.

Study Sites and Sampling Procedure. This study was conducted during the period pumpkins bloom (July to September) in the Finger Lakes region of New York in 2008 and 2009. Thirty-five pumpkin fields (2008: $\mathrm{n}=$ $12 ; 2009: \mathrm{n}=23$ ) were sampled in this study, ranging from 0.6 to 26.3 ha (average field size was $3.5 \mathrm{ha}$ ). 
Fields were selected with no prior knowledge as to whether they would or would not be supplemented with hives, different fields were used each year, and the majority of fields were commercial fields. Six of the commercial fields in 2008 and in 2009 were supplemented with A. mellifera hives. In addition to the commercial fields, each year several fields were located at Cornell University's New York State Agricultural Experiment Station (NYSAES). The average $( \pm \mathrm{SE})$ field size of supplemented fields was $6.7 \pm 1.9$ ha (range: $2.0-26.3 \mathrm{ha}$ ) and the average $( \pm \mathrm{SE}$ ) field size of nonsupplemented fields was $1.9 \pm 0.5$ ha (range: 0.6-10.9 ha).

Within each field, flowers from plants were sampled in three 10-m transects along each of the fields' four sides and three 10-m transects in the center of the field. Plants in most fields were in rows spaced $1.5 \mathrm{~m}$ apart and plants were spaced $1 \mathrm{~m}$ apart within rows. The sampling unit was a transect that consisted of two rows $\left(3 \mathrm{~m}\right.$ by $10 \mathrm{~m}$ in length $\left[\right.$ area $\left.\left.=30 \mathrm{~m}^{2}\right]\right)$ that included 20 plants. The total number of bees visiting pumpkin flowers in each transect in each field was counted once a week for three consecutive weeks, which spanned the majority of the period flowers were produced. In total, 300 plants were sampled each week in each field $(=3$ transects $\times 5$ locations in field $\times 20$ plants $=300$ plants) and, for each year, bees were sampled from a total of 900 plants per field $(=300$ plants $\times 3$ sampling dates). Though the number of plants sampled was constant, the number of flowers sampled per field per sampling date varied between 378 and 1958 (average \pm SE: $803 \pm 32$ ).

Sampling was conducted between 0600-1100 hours EDST on sunny to partly cloudy days with minimal wind. Transects were sampled in 5- to 10-min intervals by slowly walking in between the two rows, and flowers on each plant were sampled for $\approx 10-15 \mathrm{~s}$. Observers scored the number of bee visits to flowers on each plant in the transect, bee species, sex of flower, and number of flowers in the transect. A "visit" was recorded if the bee came in contact with any of the floral parts. Because not all field observers could reliably differentiate the sex of bees visiting flowers, this information was not recorded. A subsample of insect visitors were collected and identified in the lab, and voucher specimens were deposited at the Insect Collections at Cornell University (CUIC), Ithaca, NY.

Bee Pollinator Survey. Every bee species encountered visiting pumpkin flowers was identified during the 2008 and 2009 seasons. The total number of bee visits for each species was calculated for each year by summing the number of visits over time for the 12 fields in 2008 and the 23 fields in 2009. The mean number of bee visits per field also was calculated separately for each year. Because A. mellifera, B. impatiens, and $P$. pruinosa were the most common species visiting flowers in this study, the following sections focus on these species.

Flower Preference and Nectar Studies. To determine if visitation to pistillate and staminate flowers was influenced by nectar volume or concentration, nectar production was measured in pumpkin flowers,
Cucurbita pepo variety 'Mystic Plus' F1, in two fields in 2008 and two fields in 2009 located at NYSAES. Nectar from other pumpkin varieties was not sampled because volume and concentration are similar among $C$. pepo varieties (Ashworth and Galetto 2002, Hladun and Adler 2009). Flower buds were randomly selected a day before they were expected to open and bagged with nylon mesh screen to exclude insect visitors and to minimize effects on nectar production (Wyatt et al. 1992). On the morning of anthesis, the nylon mesh screen was removed and nectar was collected by destructively sampling flowers and removing petals and obstructive floral tissue by using clean razor blades. Nectar was extracted from the base of the nectary using 50- $\mu$ l micropipette tubes (Drummond Scientific Co., Broomall, PA), and the volume was calculated based on the length of the nectar column in the micropipette tubes by using published conversion protocols (Kearns and Inouye 1993). Nectar concentrations were measured as sucrose equivalents by using a hand-held refractometer (Eclipse 45- 03, Bellingham and Stanley, Tunbridge Wells, United Kingdom), which was washed with distilled water and wiped dry between samples. Differences between the total number of bee visits summed over the three sample dates to staminate and pistillate flowers and the natural sex ratio of flowers in the fields were analyzed using $\chi^{2}$ tests. Statistical analyses for flower preferences were performed using SPSS 14.0 software (SPSS 2005).

Foraging Dynamics Between Bee Species within Flowers. The mean number of bee visits per flower by A. mellifera, B. impatiens, and P. pruinosa visiting pumpkin flowers was compared for each of the three weeks separately. Data were collected as described in the Study Sites and Sampling Procedure section. Because commercial fields were planted at different times resulting in various starting bloom dates, each field was standardized at the onset of flowering so that the first sampling date (week 1) was approximately 1 wk after initial pumpkin flowering for that particular field. Initial bloom times for individual fields varied from 1 to $5 \mathrm{~d}$.

Data were analyzed separately for each sample date, for each year and for fields supplemented or not supplemented with A. mellifera hives by using PROC GLM (SAS Institute 2007). Means were compared using LSMEANS at $P<0.05$ (SAS Institute 2007). The response variable was the mean number of bee visits per flower per field for each sample date for each species and the independent variable was the bee species. Data were normalized using the $\log _{e}$ transformation before analysis. For B. impatiens, the number of visits per flower was adjusted by adding 0.01 before transformation so that dates when no B. impatiens were observed could be included in the analyses. Untransformed means are presented in the results.

Effects of Supplementation, Field Size and Other Bee Species on Bee Visits. All regression models were analyzed using PROC GLM (SAS Institute 2007). For all analyses, the response variable was the mean number of bee visits per flower calculated by summing bee visits and dividing by the total number of flowers for 
each field for each sample date, then averaging across the three sample dates for each field. The independent variables labeled field size, mean number of flowers, and mean number of bee visits per flower were $\log _{\mathrm{e}^{-}}$ transformed before analysis. For B. impatiens, the number of visits per flower was adjusted by adding 0.01 before transformation so that dates when no $B$. impatiens were observed could be included in the analyses. Type III sums of squares were used to assess the significance of variables in the regression models. If the regression model was not significant, $P$ values are only presented in the text for the overall model and not for the individual main effect terms. Interaction terms that were not significant $(P>0.05)$ were not included in the final models. Significant interactions were analyzed by separating the data by a categorical variable (supplementation or year) and reanalyzing each subset of data. Figures show results by using untransformed data.

All Three Species Combined. The regression model tested for the effects of supplementation with A. mellifera hives, field size, mean number of flowers per field and year on the mean number of bee visits per flower, also included all 2- and 3-way interaction terms. There were significant interactions between year and the number of flowers per field, and between whether a field was supplemented and field size. Separate regression models were estimated for each year testing supplementation, field size, and the mean number of flowers and all 2-way interaction terms, and separate regression models were estimated for fields that were supplemented and fields that were not supplemented testing the effects of field size, mean number of flowers and year, and all 2-way interaction terms. For nonsupplemented fields, the regression showed significant interactions between year and field size, and between year and the number of flowers per field. The data for nonsupplemented fields was analyzed further by year to estimate the effects of field size and the number of flowers per field and the 2- way interaction between field size and the number of flowers.

A. mellifera and B. impatiens Combined. Preliminary results and previous research (Artz and Nault 2011) suggested that the role of $P$. pruinosa may not be as important in determining final fruit yield as the other two species. A separate regression using the mean number of total A. mellifera and B. impatiens flower visits and excluding visits by $P$. pruinosa was used to estimate the relationship between bee visits by these two species and testing the effects of supplementation, field size, mean number of flowers per field and year, and included all 2- and 3-way interaction terms.

A. mellifera. The regression model testing the effects of supplementation, field size, mean number of flowers, year, and the mean number of bee visits per flower for B. impatiens and P. pruinosa on the mean number of A. mellifera visits per flower included all 2 -way interaction terms. There were significant interactions between supplementation and field size, number of flowers and year, and the data were further analyzed separately by whether the field was supplemented or not, and separately by year.

B. impatiens. The regression model testing the effects of supplementation, field size, mean number of flowers, year, and the mean number of bee visits per flower for A. mellifera and P. pruinosa on the mean number of $B$. impatiens visits per flower included all 2 -way interaction terms. There were significant interactions between supplementation and field size and the data were further analyzed separately by whether the field was supplemented or not.

P. pruinosa. The regression model testing the effects of supplementation, field size, mean number of flowers, year, and the mean number of bee visits per flower for A. mellifera and B. impatiens on the mean number of $P$. pruinosa visits per flower included all 2-way interaction terms. There were significant interactions between supplementation and the mean number of $A$. mellifera visits per flower and the data were further analyzed separately by whether the field was supplemented or not.

P. pruinosa Foraging Behavior. During data collection we observed that $P$. pruinosa appeared to avoid foraging in pumpkin flowers that contained A. mellifera and B. impatiens workers. To examine this possibility, the proportion of flower visits to flower approaches by $P$. pruinosa for flowers that contained a single dead A. mellifera worker, a dead B. impatiens worker, or no bee was compared. This experiment was conducted in a 0.6-ha pumpkin (Cucurbita pepo L., variety 'Mystic Plus' F1) field located at NYSAES in 2010. Data were collected from 30 August to 2 September between $0700-1000$ hours on replicate clusters of three staminate pumpkin flowers $(\mathrm{n}=48)$. Flowers were selected that were as close to each other (10-75 $\mathrm{cm}$ apart) as possible. For each group, flowers were randomly assigned either a dead A. mellifera worker, dead B. impatiens worker, or nothing (control flower). Bees used in the experiment were cyanide-killed the week before the experiment and then positioned on the petal of the flower. Observers sat 1-1.5 m away and watched flowers for $30 \mathrm{~min}$ and recorded approaches and visits by $P$. pruinosa to any of the experimental flowers. An approach to one of the experimental flowers by P. pruinosa was counted only if it oriented to the flower and flew within $10 \mathrm{~cm}$. A visit was counted if $P$. pruinosa landed on the experimental flower. Male and female P. pruinosa were not distinguished. Tests of two proportions were used to compare proportions of visits between flowers with dead A. mellifera and control flowers, between flowers with dead B. impatiens and control flowers, and between flowers with dead $A$. mellifera and flowers with dead B. impatiens (Zar 1999).

\section{Results}

Bee Pollinator Survey. Sixteen species of bees, including A. mellifera, representing 13 genera and three families, were observed and collected from pumpkin flowers from 35 commercial fields in the Finger Lakes region of New York (Table 1). A. mellifera, B. impa- 
Table 1. Bee species observed in 35 pumpkin fields in New York in $2008(n=12)$ and $2009(n=23)$

\begin{tabular}{lcc}
\hline \hline \multicolumn{1}{c}{ Family and species } & $\begin{array}{c}\text { Total numbers } \\
\text { (mean per field) in 2008 }\end{array}$ & $\begin{array}{c}\text { Total numbers } \\
\text { per field) in 2009 }\end{array}$ \\
\hline APIDAE: & & \\
Apis mellifera L. $^{a}$ & $1,747(146)$ & $3,577(156)$ \\
Bombus (Pyrobombus) impatiens (Cresson) & $1,272(106)$ & $384(17)$ \\
Melissodes (Melissodes) bimaculata Lepeletier & $24(2)$ & $69(3)$ \\
Peponapis (Peponapis) pruinosa (Say) & $2,585(215)$ & $3,344(145)$ \\
Triepeolus (Doeringiella) remigatus (F.) & $3(0.3)$ & $3(0.1)$ \\
Xylocopa (Xylocopoides) virginica (L.) & $0(0)$ & $1(0)$ \\
HALICTIDAE: & $2(0.2)$ & $2(0.1)$ \\
Agapostemon sericeus (Forster) & $2(0.2)$ & $0(0)$ \\
Augochlora pura (Say) & $4(0.3)$ & $0(0)$ \\
Augochlorella aurata (Smith) & $1(0.1)$ & $9(0.4)$ \\
Augochloropsis metallica (F.) & $3(0.3)$ & $2(0.1)$ \\
Halictus (Halictus) ligatus Say & $0(0)$ & $1(0)$ \\
Halictus (Halictus) rubicundus (Christ) & $2(0.2)$ & $0(0)$ \\
Lasioglossum (Lasioglossum) coriaceum (Smith) & $17(1.4)$ & $1(0)$ \\
Lasioglossum (Lasioglossum) leucozonium (Schrank) ${ }^{a}$ & $7(0.6)$ & $0(0)$ \\
Lasioglossum (Lasioglossum) zonulum (Smith) & & $0(0)$ \\
MEGACHILIDAE: & $1(0.1)$ & $7,393(321)$ \\
Megachile (Callomegachile) sculpturalis Smith ${ }^{a}$ & $5,670(473)$ & \\
Total bee abundance & &
\end{tabular}

${ }^{a}$ Introduced species

Total numbers represent the number of bee visits to 900 plants per field ( 300 plants $\times 3$ weekly sampling dates). Mean numbers represent average number of bee visits per field for each species. Each flower was visually inspected for bees for 10-15 s.

tiens, and P. pruinosa were the most abundant pumpkin floral visitors in both years and they represented $99 \%$ of all bee visits to flowers (Table 1). B. impatiens was the only species of Bombus recorded from pumpkin flowers throughout the 2-yr study. In total, 13 and 10 non-Apis bee species were recorded visiting pumpkin flowers in 2008 and 2009, respectively (Table 1).

A. mellifera, B. impatiens, and P. pruinosa were observed in all 35 fields sampled. Mean number of flower visits per field by A. mellifera, B. impatiens, and $P$. pruinosa varied between years and among fields sampled (A. mellifera range $=47-389$ in 2008; range $=$ $74-341$ in 2009; B. impatiens range $=42-224$ in 2008; range $=2-51$ in 2009; $P$. pruinosa range $=32-998$ in 2008 ; range $=46-389$ in 2009). Overall, there was a similar mean number of A. mellifera visits to pumpkin flowers per field in 2008 and 2009 (Table 1). In contrast, there were six times more B. impatiens visits per field in 2008 than in 2009 , and there were more $P$. pruinosa visits on average per field in 2008 than in 2009 (Table 1). The remainder of this paper focuses on foraging activity by A. mellifera, B. impatiens, and $P$. pruinosa.

Flower Preference and Nectar Studies. A. mellifera visited significantly more pistillate flowers than they would have if they randomly visited pistillate and staminate flowers in the field in $2008\left(\chi^{2}{ }_{1}=20.7 ; P<\right.$ $0.001 ;$ Fig. 1A) and $2009\left(\chi_{1}^{2}=16.4 ; P<0.001 ;\right.$ Fig. 1B). B. impatiens also visited significantly more pistillate flowers than expected by chance in $2008\left(\chi^{2}{ }_{1}=4.3\right.$; $P=0.038$; Fig. 1A $)$ and $2009\left(\chi_{1}^{2}=5.5 ; P=0.019\right.$; Fig. 1B). P. pruinosa visits to pistillate and staminate flowers mirrored the natural proportion of pistillate and staminate flowers in the fields in $2008\left(\chi_{1}^{2}=0 ; P=1.0\right.$; Fig. 1A) and $2009\left(\chi_{1}^{2}=0 ; P=1.0\right.$; Fig. 1B).

Pistillate flowers produced on average three times more nectar than staminate flowers in all four fields
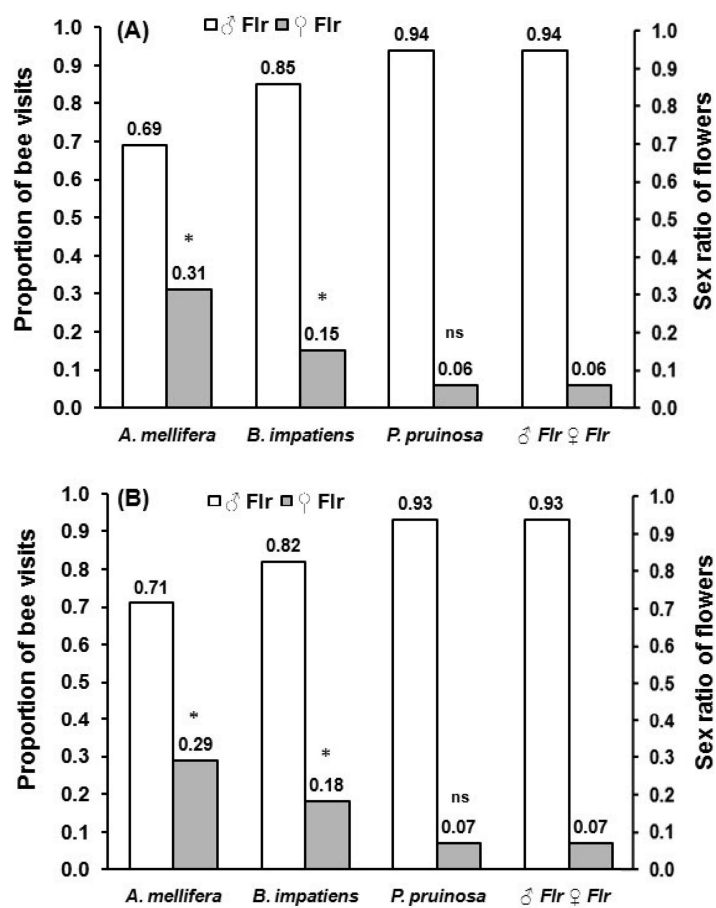

Fig. 1. Visits by Apis mellifera, Bombus impatiens, and Peponapis pruinosa to staminate and pistillate pumpkin flowers in New York commercial fields in (A) 2008 and (B) 2009. A total of 33,752 flowers were sampled in 2008 pooled across 12 fields. A total of 50,573 flowers were sampled in 2009 pooled across 23 fields. Asterisks over columns indicate significant $(P<0.001)$ differences between the proportion of bee visits to pistillate flowers compared with the natural proportion of pistillate flowers in fields. 
Table 2. Nectar volume and concentration in Cucurbita pepo var. 'Mystic Plus' F1 sampled from NYSAES Research Farms in 2008 and 2009

\begin{tabular}{|c|c|c|c|c|c|c|c|c|c|c|}
\hline & & & \multicolumn{3}{|c|}{ Nectar vol. $^{a}$} & & \multicolumn{4}{|c|}{ Nectar concn. $^{a}$} \\
\hline & & & Field name & & Field name & & Field name & & Field name & \\
\hline Year & Flower & $N$ & RS 59 & & RN 41 & & RS 59 & & RN 41 & \\
\hline \multirow[t]{2}{*}{2008} & Staminate & 10 & $39.41 \pm 3.93$ & $\mathrm{a}$ & $30.94 \pm 2.04$ & $\mathrm{a}$ & $41.05 \pm 0.58$ & $\mathrm{a}$ & $39.10 \pm 0.43$ & a \\
\hline & Pistillate & 10 & $93.64 \pm 17.97$ & $\mathrm{~b}$ & $84.16 \pm 6.33$ & $\mathrm{~b}$ & $36.05 \pm 0.46$ & $\mathrm{~b}$ & $39.50 \pm 0.40$ & $\mathrm{a}$ \\
\hline Year & Flower & $N$ & RN 47 & & Gates 20 & & RN 47 & & Gates 20 & \\
\hline \multirow[t]{2}{*}{2009} & Staminate & 10 & $26.50 \pm 2.92$ & $\mathrm{a}$ & $37.71 \pm 2.95$ & $\mathrm{a}$ & $40.05 \pm 2.38$ & $\mathrm{a}$ & $39.45 \pm 0.47$ & $\mathrm{a}$ \\
\hline & Pistillate & 10 & $95.53 \pm 7.55$ & $\mathrm{~b}$ & $107.26 \pm 6.63$ & $\mathrm{~b}$ & $40.65 \pm 0.68$ & $\mathrm{a}$ & $40.45 \pm 0.42$ & $\mathrm{a}$ \\
\hline
\end{tabular}

${ }^{a}$ For each year, means within a column with different letters are significantly different $(P<0.05)$.

Flowers were bagged the day before and destructively sampled the next morning at anthesis. Numbers represent mean \pm SE. Nectar volume is in $\mu \mathrm{l}$ and nectar concentration is in \% sucrose equivalents.

sampled across both years $($ mean $\pm \mathrm{SE})(q=95.2 \pm$ $5.3 \mu \mathrm{l} ; \delta^{\text {o }}=33.6 \pm 1.7 \mu \mathrm{l}$ ) (Table 2). There was no difference in nectar concentration between pistillate flowers and staminate flowers in three of four fields sampled, but staminate flowers had statistically more concentrated nectar than pistillate flowers in one of the four fields sampled (mean $\pm \mathrm{SE}) \quad(q=36.1 \% \pm$ $0.5 ; 0=41.1 \% \pm 0.6$ ) (Table 2 ).

Foraging Dynamics Between Bee Species Within Flowers. 2008. The only significant differences in the number of visits per flower between the three bee species occurred on week 2 in both nonsupplemented and supplemented fields. In pumpkin fields not supplemented with A. mellifera, there were consistently more P. pruinosa visits to pumpkin flowers each week compared with the number of visits by A. mellifera and B. impatiens, but this difference was only significant on week $2(F=5.6 ; \mathrm{df}=2,15 ; P=0.0155)$ (Fig. $2 \mathrm{~A})$. There was no difference between the number of flower visits by A. mellifera and B. impatiens on any of the 3 wk. In pumpkin fields supplemented with $A$. mellifera, there were consistently more A. mellifera visits to pumpkin flowers each week compared with the number of visits by B. impatiens and P. pruinosa, and the difference was also only significant on week 2 $(F=5.5 ; \mathrm{df}=2,15 ; P=0.0158)$ (Fig. 2B). There were no significant differences between flower visits by $B$. impatiens and P. pruinosa.

2009. In pumpkin fields not supplemented with $A$. mellifera, there were significantly more A. mellifera and $P$. pruinosa visits to pumpkin flowers each week compared with the number of visits by $B$. impatiens (week 1: $F=32.1 ; \mathrm{df}=2,48 ; P<0.0001$; week $2: F=$ $28.2 ; \mathrm{df}=2,48 ; P<0.0001$; week $3: F=19.1 ; \mathrm{df}=2$,


Fig. 2. Mean number of Apis mellifera, Bombus impatiens, and Peponapis pruinosa visits per flower per field during a 3-wk period in fields (A and C) not supplemented or (B and D) supplemented with A. mellifera hives in 2008 and 2009 in New York. Columns represent total mean bee visits broken down within each column by species. Asterisks over columns indicate at least one significant difference between bee species $(P<0.05$, PROC GLM). 
Table 3. Generalized linear model regression results testing the effects of supplementation with $A$. mellifera hives, field size, mean number of flowers per field and year for the three species combined, and for each species independently

\begin{tabular}{|c|c|c|c|c|c|c|}
\hline Species & Source/variable ${ }^{a}$ & $\mathrm{df}$ & Estimate $^{b}$ & $F$ & $P$ & $R^{b}$ \\
\hline \multirow{7}{*}{$\begin{array}{l}\text { A. mellifera, } \\
\text { B. impatiens, and } \\
\text { P. pruinosa combined }\end{array}$} & Overall model, error & 6,28 & - & 3.65 & 0.0083 & 0.44 \\
\hline & Supplementation & 1 & - & 11.51 & 0.0021 & \\
\hline & Field size & 1 & - & 1.11 & 0.3002 & \\
\hline & Mean no. of flowers & 1 & -3.72 & 8.09 & 0.0082 & \\
\hline & Year & 1 & -12.37 & 5.21 & 0.0303 & \\
\hline & Supplementation*field size & 1 & - & 6.96 & 0.0135 & \\
\hline & Mean no. of flowers*year & 1 & - & 4.88 & 0.0355 & \\
\hline \multirow[t]{10}{*}{ A. mellifera } & Overall model, error & 9,25 & & 3.65 & 0.0049 & 0.57 \\
\hline & Supplementation & 1 & - & 5.61 & 0.0259 & \\
\hline & Field size & 1 & - & 1.95 & 0.1750 & \\
\hline & Mean no. of flowers & 1 & - & 3.71 & 0.0655 & \\
\hline & Year & 1 & - & 0.01 & 0.9378 & \\
\hline & B. impatiens per flower & 1 & -0.0689 & 0.81 & 0.3769 & \\
\hline & P. pruinosa per flower & 1 & -0.2598 & 4.37 & 0.0469 & \\
\hline & Supplementation*field size & 1 & - & 4.48 & 0.0444 & \\
\hline & Supplementation*flowers & 1 & - & 5.58 & 0.0262 & \\
\hline & Supplementation*year & 1 & - & 5.45 & 0.0279 & \\
\hline \multirow[t]{8}{*}{ B. impatiens } & Overall model, error & 7,27 & & 9.08 & $<0.0001$ & 0.70 \\
\hline & Supplementation & 1 & - & 2.62 & 0.1172 & \\
\hline & Field size & 1 & - & 0.59 & 0.4483 & \\
\hline & Mean no. of flowers & 1 & -4.2594 & 7.72 & 0.0098 & \\
\hline & Year & 1 & -3.1199 & 32.39 & $<0.0001$ & \\
\hline & A. mellifera per flower & 1 & -0.5444 & 1.58 & 0.2196 & \\
\hline & P. pruinosa per flower & 1 & -0.5804 & 3.58 & 0.0693 & \\
\hline & Supplementation*field size & 1 & - & 6.77 & 0.0148 & \\
\hline \multirow[t]{8}{*}{ P. pruinosa } & Overall model, error & 7,27 & & 4.27 & 0.0027 & 0.53 \\
\hline & Supplementation & 1 & - & 7.41 & 0.0112 & \\
\hline & Field size & 1 & -0.1372 & 0.87 & 0.3580 & \\
\hline & Mean no. of flowers & 1 & -0.8300 & 0.99 & 0.3279 & \\
\hline & Year & 1 & -0.2510 & 0.37 & 0.5488 & \\
\hline & A. mellifera per flower & 1 & - & 0.99 & 0.3290 & \\
\hline & B. impatiens per flower & 1 & -0.1460 & 2.35 & 0.1366 & \\
\hline & Supplementation*A. mellifera & 1 & - & 10.08 & 0.0037 & \\
\hline
\end{tabular}

${ }^{a} \mathrm{~A}$ “*” indicates a significant interaction between these two terms in the model.

${ }^{b}$ A “-” indicates estimates for this parameter were not uniquely estimable using PROC GLM (SAS v. 9.1).

For the three individual species, additional variables representing the mean number of flower visits per flower for the other two bee species

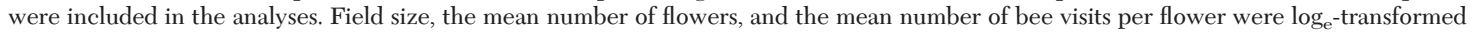
before analysis. Nonsignificant interaction terms $(P>0.05)$ were not included in the final models.

48; $P<0.0001$ ) (Fig. 2C). The number of visits per flower by A. mellifera and P. pruinosa did not differ significantly on any sampling date $(P>0.05)$. Results were similar for pumpkin fields supplemented with $A$. mellifera; there were significantly more visits to pumpkin flowers by $A$. mellifera and P. pruinosa than by $B$. impatiens (week 1: $F=12.7$; df $=2,15 ; P=0.0006$; week 2: $F=24.0$; $\mathrm{df}=2,15 ; P<0.0001$; week $3: F=$ 7.9 ; $\mathrm{df}=2,15 ; P=0.0046$ ) (Fig. 2D), and there were no significant differences between flower visits by $A$. mellifera and P. pruinosa.

Effects of Supplementation, Field Size, and Other Bee Species on Bee Visits. The presence or absence of A. mellifera hives, field size, the mean number of flowers per field and year were all significant factors in predicting the mean number of bee visits per flower for different combinations of the three bee species and each species alone (Table 3).

All Three Species Combined. Fields supplemented with A. mellifera hives had significantly fewer total bee visits per flower than nonsupplemented fields (mean $\pm \mathrm{SE})$ (supplemented fields: $=0.136 \pm 0.013$ bees per flower; nonsupplemented fields: $=0.184 \pm$ 0.02 bees per flower) (Fig. 3). Field size was not a significant factor on its own in predicting the total number of bee visits but there was a significant interaction between field size and supplementation. There were significantly more bee visits per flower in 2008 than in $2009($ mean $\pm \mathrm{SE})(2008:=0.191 \pm 0.036$ bees per flower; 2009: $=0.156 \pm 0.011$ bees per flower). There was a significant negative relationship between the number of flowers per field and the number of bee visits per flower; the more flowers per field the fewer bee visits per flower (Table 3 ).

In the first regression model there were two significant interactions; one between year and the number of flowers per field, and one between whether a field was supplemented and field size (Table 3). Separate regression models were estimated for each year testing supplementation, field size and the number of flowers and neither model was significant (2008: model, $F=3.2$; error $\mathrm{df}=4,7 ; P=0.0857 ; 2009$ : model, 


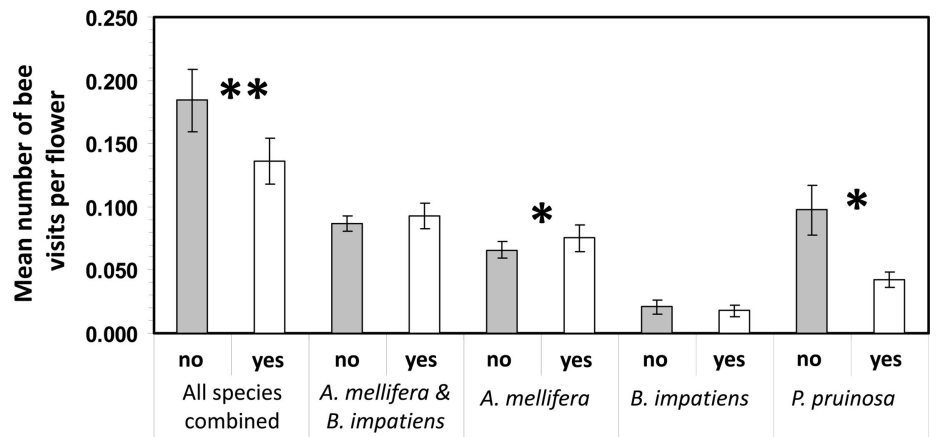

Supplementation with $A$. mellifera

Fig. 3. Mean number of bee visits per flower per field for pumpkin fields supplemented and not supplemented with Apis mellifera hives in New York in 2008 and 2009. Significant differences between the number of bee visits in supplemented and nonsupplemented fields are indicated with ** for $P<0.01$ and with * for $P<0.05$.

$F=1.7$; error $\mathrm{df}=4,18 ; P=0.1960)$. However, when the data were analyzed separately based on whether the field was supplemented with A. mellifera hives or not, there were significant relationships, but only for fields that were nonsupplemented; the regression model for supplemented fields was not significant (Supplemented: model, $F=0.9$; error $\mathrm{df}=5,6 ; P=$ 0.5447 ). For fields that were not supplemented with $A$. mellifera hives, there was a significant effect of field size, the mean number of flowers, and year on the number of total bee visits per flower (Table 4 ). The number of total bee visits per flower decreased as both field size increased and the number of flowers increased (Table 4). In addition, there were significantly more bee visits per flower in 2008 than in 2009 (mean $\pm \mathrm{SE})(2008:=0.245 \pm 0.064$ bee visits per flower; 2009: $=0.163 \pm 0.014$ bee visits per flower). There were also significant interactions between year and field size and between year and the number of flowers per field (Table 4). The data for nonsupplemented fields were analyzed separately by year to address these interactions. In 2008, both field size and

Table 4 Generalized linear model regression results for fields that were not supplemented with $\boldsymbol{A}$. mellifera hives testing the effects of field size, mean number of flowers per field, and year for the three species combined, and for each species independently

\begin{tabular}{|c|c|c|c|c|c|c|}
\hline Species & Source/variable & $\mathrm{df}$ & Estimate & $F$ & $P$ & $\overline{R^{2}}$ \\
\hline \multirow{6}{*}{$\begin{array}{l}\text { A. mellifera, } \\
\text { B. impatiens, and } \\
\text { P. pruinosa combined }\end{array}$} & Overall model, error & 5,17 & & 5.62 & 0.0031 & 0.62 \\
\hline & Field size & 1 & -5.5622 & 7.69 & 0.0130 & \\
\hline & Mean no. of flowers & 1 & -17.2747 & 12.02 & 0.0029 & \\
\hline & Year & 1 & -59.1067 & 11.94 & 0.0030 & \\
\hline & Field size* year & 1 & 2.7308 & 7.38 & 0.0147 & \\
\hline & Flowers*year & 1 & 8.6983 & 11.79 & 0.0032 & \\
\hline \multirow[t]{6}{*}{ A. mellifera } & Overall model, error & 5,17 & & 6.21 & 0.0019 & 0.65 \\
\hline & Field size & 1 & -0.1420 & 1.12 & 0.3043 & \\
\hline & Mean no. of flowers & 1 & -0.0072 & 0.00 & 0.9921 & \\
\hline & Year & 1 & 0.4056 & 1.12 & 0.3043 & \\
\hline & B. impatiens per flower & 1 & -0.0918 & 1.42 & 0.2502 & \\
\hline & P. pruinosa per flower & 1 & -0.3757 & 8.59 & 0.0093 & \\
\hline \multirow[t]{6}{*}{ B. impatiens } & Overall model, error & 5,17 & & 7.92 & 0.0005 & 0.70 \\
\hline & Field size & 1 & -0.9937 & 8.44 & 0.0099 & \\
\hline & Mean no. of flowers & 1 & -4.4593 & 5.68 & 0.0291 & \\
\hline & Year & 1 & -3.2681 & 13.36 & 0.0020 & \\
\hline & A. mellifera per flower & 1 & -0.8386 & 1.42 & 0.2502 & \\
\hline & P. pruinosa per flower & 1 & -0.8464 & 3.90 & 0.0649 & \\
\hline \multirow[t]{6}{*}{ P. pruinosa } & Overall model, error & 5,17 & & 3.69 & 0.0192 & 0.52 \\
\hline & Field size & 1 & -0.3550 & 3.31 & 0.0867 & \\
\hline & Mean no. of flowers & 1 & -1.6839 & 2.70 & 0.1184 & \\
\hline & Year & 1 & -0.6305 & 1.14 & 0.3002 & \\
\hline & A. mellifera per flower & 1 & -0.8932 & 8.59 & 0.0093 & \\
\hline & B. impatiens per flower & 1 & -0.2203 & 3.90 & 0.0649 & \\
\hline
\end{tabular}

For the three individual species, additional variables representing the mean number of flower visits per flower for the other two bee species


before analysis. Nonsignificant interaction terms $(P>0.05)$ were not included in the final models. 
the number of flowers had significant negative relationships with the mean total number of bee visits (Nonsupplemented fields 2008: model, $F=14.9$; error df $=2,3 ; P=0.0278$; field size: $F=12.6 ; \mathrm{df}=1$, estimate $=-2.8314 ; P=0.0380 ;$ mean number of flowers: $F=19.0$; $\mathrm{df}=1$, estimate $=-8.5764 ; P=$ $0.0224)$. In 2009 , the regression model testing field size and number of flowers was not significant (Nonsupplemented fields 2009: model, $F=0.9$; error $\mathrm{df}=$ $2,14 ; P=0.4213)$.

There were individual fields in the nonsupplemented data set that appeared to be influential. The nonsupplemented data were reanalyzed excluding the largest field, 10.9 ha, and the qualitative results for main effects and interactions presented in Table 4 remained significant (Nonsupplemented fields minus largest field: model, $F=5.1$; error $\mathrm{df}=5,16 ; P=$ 0.0054 ). However, excluding the field that had the highest number of bee visits per flower, 0.55 bee visits per flower, changed the regression and the regression model presented in Table 4 was not significant (Nonsupplemented fields minus field with highest bee visits per flower: model, $F=1.5$; error $\mathrm{df}=5,16 ; P=0.2375$ ). Regression models excluding the interaction terms with year also were not significant, and the reduced model, including only field size, mean number of flowers, and year was not significant (Nonsupplemented fields minus field with highest bee visits per flower: model, $F=1.0$; error $\mathrm{df}=3,18 ; P=0.4067$ ).

A. mellifera and B. impatiens Combined. When the mean number of flower visits by $P$. pruinosa was excluded from the analysis, interactions were not significant and the regression model for A. mellifera and B. impatiens combined consisting of only the four main effect terms (supplementation, field size, year, and mean number of flowers per field) was not significant (model, $F=0.4$; error $\mathrm{df}=4,30 ; P=0.8425$ ) (Fig. 3).

A. mellifera. Supplementation was a significant factor affecting the mean number of visits to pumpkin flowers by A. mellifera. The number of A. mellifera visits per flower in supplemented fields was significantly greater than the number of A. mellifera visits in nonsupplemented fields (mean $\pm \mathrm{SE}$ ) (Supplemented fields: $=0.075 \pm 0.01$ A. mellifera per flower; nonsupplemented fields: $=0.066 \pm 0.007$ A. mellifera per flower) (Fig. 3) (Table 3). The number of flower visits by $P$. pruinosa had a significant negative effect on the number of flower visits by A. mellifera; as the number of $P$. pruinosa visits per flower increased, the number of A. mellifera visits decreased (Fig. 4) (Table 3 ). Field size was not a significant factor as a main effect, but there was a significant interaction between supplementation and field size, and there were significant interactions between supplementation and the number of flowers per field and year (Table 3). Separate regression models were estimated for supplemented and nonsupplemented fields. The regression model that included only fields that were supplemented with $A$. mellifera hives was not significant (A. mellifera: model, $F=1.3$; error $\mathrm{df}=5,6 ; P=$ 0.3711 ). In fields that were not supplemented, there was a significant negative relationship between the

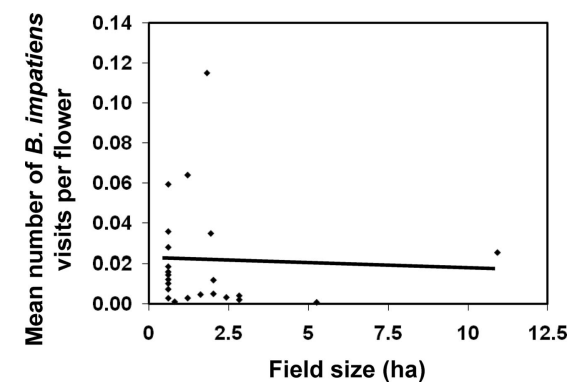

Fig. 4. Relationship between the mean number of flower visits by Apis mellifera and the mean number of flower visits by Peponapis pruinosa in fields that were not supplemented with A. mellifera hives in New York in 2008 and $2009(P<$ 0.05, PROC GLM).

number of flower visits by P. pruinosa and the number of flower visits by A. mellifera, which was similar to the results for all fields combined (Table 4). Field size, the number of flowers, and year were not significant factors predicting the mean number of flower visits by $A$. mellifera in nonsupplemented fields (Table 4).

B. impatiens. The mean number of flowers and year were significant main effect factors predicting the number of B. impatiens visits per pumpkin flower. As the number of flowers per field increased the number of visits by $B$. impatiens decreased, and there were significantly more visits by $B$. impatiens in 2008 than in 2009 (mean \pm SE) $(2008:=0.043 \pm 0.008$ B. impatiens visits per flower; 2009: $=0.008 \pm 0.001 \mathrm{~B}$. impatiens visits per flower) (Table 3). The number of flower visits by the other two species did not affect the number of B. impatiens visits per flower (Table 3). There was a significant interaction between supplementation and field size, but neither supplementation nor field size alone were significant main effect factors (Fig. 3) (Table 3). Separate regression models were estimated for supplemented and nonsupplemented fields, and the regression model for fields that were supplemented with $A$. mellifera hives was not significant (B. impatiens: model, $F=4.0$; error $\mathrm{df}=5,6 ; P=$ 0.0612 ). In fields that were not supplemented, there was a significant negative relationship between field size and flower visits by $B$. impatiens; as field size increased the number of $B$. impatiens visits per flower decreased (Fig. 5) (Table 4). Similar to the results of the regression that included both supplemented and nonsupplemented fields, there was a negative relationship between the number of flowers per field and the number of B. impatiens visits per flower, and there were significantly more visits by B. impatiens in 2008 than in 2009 (mean $\pm \mathrm{SE}) \quad(2008:=0.056 \pm 0.013 B$. impatiens visits per flower; 2009: $=0.008 \pm 0.002 B$. impatiens visits per flower) (Table 4).

There were individual fields in the nonsupplemented data set for B. impatiens only that appeared to be influential (Fig. 5). The nonsupplemented data were reanalyzed excluding the largest field, $10.9 \mathrm{ha}$, and the qualitative results for the regression model and all the variables in the model presented in Table 


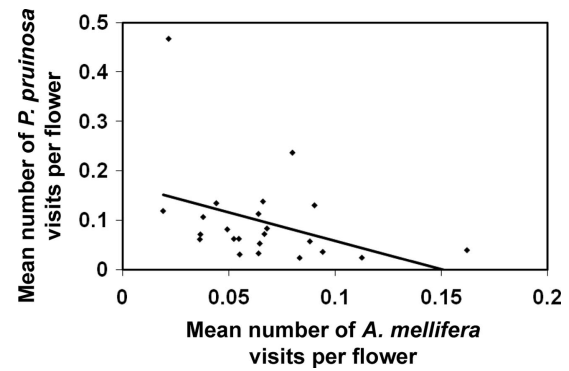

Fig. 5. Relationship between the mean number of flower visits by Bombus impatiens and field size in fields that were not supplemented with Apis mellifera hives in New York in 2008 and $2009(P<0.05$, PROC GLM $)$.

4 remained significant (Nonsupplemented fields minus largest field: model, $F=9.3$; error $\mathrm{df}=5,16 ; P=$ $0.0003)$. Excluding the field that had the highest number of B. impatiens visits per flower, 0.11 B. impatiens visits per flower, did not change the qualitative results for the regression model or the individual variable results presented in Table 4 (Nonsupplemented fields minus field with highest $B$. impatiens visits per flower: model, $F=6.2$; error $\mathrm{df}=5,16 ; P=0.0022$ ). Excluding both of these potentially influential fields did not change the qualitative results for the regression model or the individual variable results presented in Table 4 (Nonsupplemented fields minus both fields: model, $F=7.4$; error $\mathrm{df}=5,115 ; P=0.0011)$.

$P$. pruinosa. Supplementation was a significant factor affecting the mean number of visits to pumpkin flowers by P. pruinosa. The number of flower visits by P. pruinosa was significantly lower in fields supplemented with A. mellifera hives than in those fields not supplemented (mean $\pm \mathrm{SE}$ ) (Supplemented fields: $=$ $0.043 \pm 0.006$ P. pruinosa per flower; nonsupplemented fields: $=0.098 \pm 0.020$ P. pruinosa per flower) (Fig. 4) (Table 3). Field size was not a significant factor for $P$. pruinosa alone or as an interaction term (Table 3 ). The number of flower visits by A. mellifera had a significant negative effect on the number of flower visits by $P$. pruinosa (Fig. 4), and there was a significant interaction between supplementation and the mean number of A. mellifera visits per flower (Table 3). Separate regression models were estimated for supplemented and nonsupplemented fields and, for fields that were supplemented with A. mellifera hives, the regression was not significant (P. pruinosa: model, $F=0.6$; error $\mathrm{df}=5,6 ; P=0.7378)$. In fields that were not supplemented, there was a significant negative relationship between the number of flower visits by $P$. pruinosa and the number of flower visits by A. mellifera, similar to the results for all fields combined (Table 4). Field size, the number of flowers, and year were not significant factors predicting the number of flower visits by P. pruinosa in nonsupplemented fields (Table 4).

P. pruinosa Foraging Behavior. In total, 434 P. pruinosa approached one of the three treatment flowers in this study. In total, 109 P. pruinosa approached flowers containing dead A. mellifera, but only 11 approaches were classified as visits. In total, 120 P. pru-

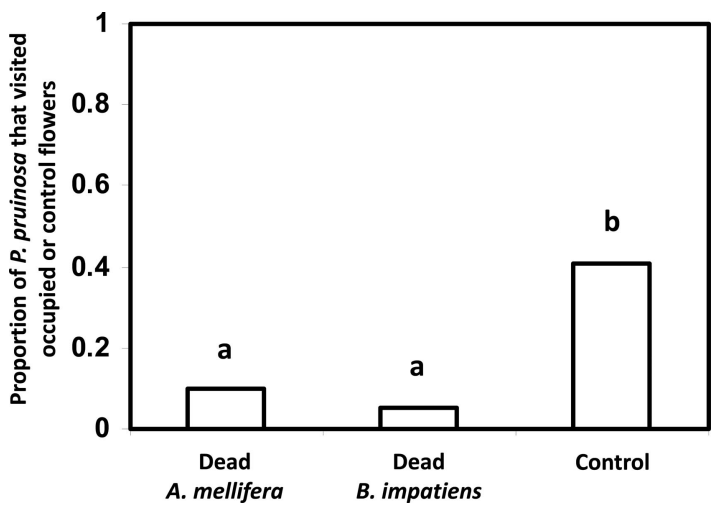

Fig. 6. Proportion of Peponapis pruinosa that visited staminate pumpkin (Cucurbita pepo variety 'Mystic Plus' F1) flowers of those that they approached when offered choices between flowers occupied by a dead Apis mellifera worker, dead Bombus impatiens worker, or no bee (control) $(n=109$, 120 and 205 for A. mellifera worker, B. impatiens worker and the control). Different letters above the bars represent significant differences at $\left(P<0.05, \chi^{2}\right)$.

inosa approached flowers containing B. impatiens, but only six visited. In contrast, control flowers received 84 $P$. pruinosa visits out of 121 approaches. A significantly greater proportion of $P$. pruinosa visited control flowers compared with the proportions visiting flowers containing dead bees (Control versus A. mellifera: $\mathbf{Z}=$ $-5.67 ; P<0.001$; Control versus $B$. impatiens: $\mathbf{Z}=$ $-6.99 ; P<0.001)$, but there was no difference between the proportions of visits to flowers with dead $A$. mellifera and dead B. impatiens (A. mellifera versus $B$. impatiens: $Z=1.47 ; P=0.1421$ ) (Fig. 6).

\section{Discussion}

A. mellifera, B. impatiens, and P. pruinosa were the most commonly observed bee species visiting pumpkin flowers in this 2-yr study, accounting for $99 \%$ of all bee visits. When the three species were combined, there were significantly more bee visits per flower in fields that were not supplemented with A. mellifera hives, which might suggest that supplementation may be negligible for improving crop production. However, pollination services provided by bees are dependent on foraging activity and, in our study, the foraging activities of these three species varied in ways that could affect their relative effectiveness as pollinators of pumpkins in New York. For example, A. mellifera and $B$. impatiens visited pistillate flowers more often than would be expected by random chance compared with $P$. pruinosa, whose visits mirrored the natural proportions of pistillate and staminate flowers in the field. The mean number of flower visits by A. mellifera and $P$. pruinosa was affected by the presence or absence of supplemental A. mellifera hives and there were significant effects of one species on the other, whereas B. impatiens was significantly affected by field size and the number of flowers in a field, and not by the presence of other bee species. The remaining 
discussion focuses on the implications of these results on pollination services provided by these three species in pumpkin fields in New York.

A. mellifera, B. impatiens, and P. pruinosa were commonly detected in all 35 pumpkin fields sampled. Julier and Roulston (2009) also noted A. mellifera, B. impatiens, and P. pruinosa as the most abundant bee species visiting pumpkins in Virginia and Maryland. The 13 other bee species in our study were rarely observed visiting flowers. The number of common bee species in our study is similar to bee faunas in other plantpollinator studies where a few species dominate (Thomson 1980, Herrera 1987, Cane and Payne 1993, Kallimanis et al. 2009). Winfree et al. (2007) reported a more diverse assemblage of bee pollinators in watermelon fields in New Jersey and Pennsylvania. Of the 46 bee species they observed visiting watermelon flowers, 32 were small halictid bees compared with nine halictid bee species in our study.

Variation in foraging behavior among the three common bee species in our study may have important influences on pollination success and crop yield (Klinkhamer and de Jong 1990, Hodgins and Barrett 2008, Elliott and Irwin 2009). Results from the flower gender preference experiment showed that the proportion of visits by $P$. pruinosa closely matched the natural sex ratio of flowers in the fields, indicating that P. pruinosa do not prefer foraging in pistillate flowers more than male flowers. In contrast, significantly more A. mellifera and B. impatiens visited pistillate flowers than would be expected by random chance, suggesting that A. mellifera and B. impatiens exhibited preferential foraging for pistillate flowers. Our findings are in agreement with those of Tepedino (1981), who found that A. mellifera showed a significant preference for pistillate summer squash, C. pepo, flowers in Utah. However, compared with P. pruinosa, A. mellifera was not a better pollinator of summer squash, despite showing a significant preference for pistillate flowers. In our study, by preferentially visiting more pistillate flowers, A. mellifera and B. impatiens increase the probability of per visit pollen transfer to stigmas during a foraging bout (Harder and Wilson 1997). Foraging and yield studies by Artz and Nault (2011) found that $B$. impatiens deposited more than three times the amount of pollen grains per stigma per visit than $A$. mellifera or $P$. pruinosa, and, of the three species, $P$. pruinosa was a less effective pollinator of pumpkin than A. mellifera and B. impatiens. Field observations of A. mellifera and B. impatiens showed that these species also spent significantly more time foraging in pistillate flowers than P. pruinosa (Artz and Nault 2011). Flower preference and flower handling time are two important parameters in explaining pollination efficiency in pollinators (Herrera 1987, Ne'eman et al. 2006) and can influence pollination success for plants with sexually dimorphic flowers (Costich and Meagher 2001, Ashworth and Galetto 2002).

An important component of pollinator attraction is the quality and quantity of floral rewards, particularly nectar and pollen (Canto et al. 2008, Kaczorowski et al. 2008). Empirical studies have shown that pheno- typic and genetic variation in nectar traits can have significant direct and indirect impacts on pollination success (Galen and Newport 1988, Mitchell 2004, Salzmann et al. 2007, Majetic et al. 2009). In our study, pistillate flowers produced significantly more nectar than staminate flowers. Both A. mellifera and B. impatiens are primarily nectar foragers collecting sucrose-rich nectar for colony support and brood expansion (Seeley 1995, Heinrich 2004), and this may be one reason why $A$. mellifera and $B$. impatiens individuals were more likely to be observed in nectar-rich pistillate flowers in 2008 and 2009.

Vegetable growers often place A. mellifera hives in pumpkin fields to ensure fruit set and increase fruit size. In our study, there were significantly more $A$. mellifera visits per flower in pumpkin fields supplemented with A. mellifera hives. However, when all three species were combined, there were significantly fewer bee visits per flower in supplemented fields. When visits by $P$. pruinosa were excluded from the analysis, there was no significant effect of supplementation on the mean number of bee visits by A. mellifera and B. impatiens combined, suggesting that though visits by $A$. mellifera were higher in supplemented fields, visits by B. impatiens made up the difference in nonsupplemented fields. When the flower visits by the three species were compared on a weekly basis, the mean number of flower visits by A. mellifera was significantly higher than the other two species on only one occasion, week 2 of 2008 in the supplemented fields. It is possible that growers who intend to enhance pollination services of their pumpkin crop by supplementing fields with $A$. mellifera hives may gain little, if any, additional pollination because B. impatiens and P. pruinosa increase the number of per flower visits in nonsupplemented fields to be equal to or exceed visits in supplemented fields.

Supplementation of pumpkin fields with A. mellifera hives had an effect on how the other bee species responded to field size, the mean number of flowers per field, and to the presence of other species of bees. For all three species, there were significant interactions between the effects of supplementation with A. mellifera hives and other factors. In nonsupplemented fields, both A. mellifera and $P$. pruinosa had significant negative effects on one another, as the mean number of flower visits by one species increased, the mean number of flower visits by the other species decreased (Fig. 4). Results from our behavioral experiment showed that P. pruinosa avoided visiting pumpkin flowers that contained either A. mellifera or B. impatiens (Fig. 6). Findings that $P$. pruinosa discriminate against flowers occupied by heterospecifics are in agreement with other studies that examined behavioral responses and flower discriminating choices by solitary and social bees (Dukas 2001, Abbott 2006, Yokoi and Fujisaki 2011).

A. mellifera may directly and indirectly compete for floral resources with native bees in both natural and agricultural ecosystems worldwide (Paini 2004, Thomson 2004, Goulson and Sparrow 2009, Shavit et al. 
2009). Moreover, many empirical studies have documented various interspecific behavioral interactions at flowers and noted that these interactions may have both negative and positive implications for pollination success (Corbet et al. 1995, Irwin and Brody 1999). For example, Greenleaf and Kremen (2006) reported an increase in honey bee effectiveness in pollination of hybrid sunflowers (Helianthus annuus L.) via behavioral interactions with the local native bee communities. Specifically, pollination efficiencies of A. mellifera increased because of displacement by foraging native bees, resulting in more A. mellifera visits, which increased seed yields attributed to the increase in pollen transfer and deposition by A. mellifera. Furthermore, despite considerable variation in pollination efficiencies of wild bees foraging on sunflower, wild bees contributed to pollination services indirectly (i.e., via behavioral interactions with A. mellifera) and directly (direct pollination) in this system. Although we do not have experimental evidence to support that pollination efficiencies of bees are negatively or positively influenced in pumpkin by the presence of supplemental A. mellifera hives, anecdotal evidence suggests that interspecific interactions in pumpkin flowers may be influencing bee movement and pollen transfer among plants. Additional experiments are planned to study behavioral responses of A. mellifera and B. impatiens to the presence of heterospecifics and to quantify interaction intensities among bees at pumpkin flowers and how these interactions affect interplant movement, pollen deposition, and pollination success.

Field size was not a significant factor predicting the mean number of A. mellifera visits per flower or the number of visits by $P$. pruinosa, but was significant for B. impatiens in nonsupplemented fields. Because $A$. mellifera is known to forage up to $12 \mathrm{~km}$ or more, and often forage for floral resources several kilometers away from their colonies (Beekman and Ratnieks 2000, Steffan-Dewenter and Kuhn 2003), it may not be as sensitive to field size as the other two species. Visscher and Seeley (1982) found that the median distance of $A$. mellifera foragers was $1.7 \mathrm{~km}$ away from colonies, and that most of the foraging activity was $>0.5 \mathrm{~km}$ away from colonies. Supplementing a crop with A. mellifera hives will provide direct pollination services to that crop because some foraging will occur near the hive, but other crops nearby are also likely to benefit as a consequence of long-distance foraging behavior by A. mellifera workers. In the mid-Atlantic United States, Shuler et al. (2005) and Julier and Roulston (2009) found a statistically similar number of $A$. mellifera visiting squash and pumpkin flowers on farms with and without A. mellifera hives, suggesting that feral or managed A. mellifera individuals, or both, move in from the surrounding landscape to forage in nonsupplemented pumpkin fields.

$P$. pruinosa is a ground-nesting bee and many ground-nesting bees restrict their nesting sites to edges of agricultural fields (Cane 2008). We observed $P$. pruinosa nests along margins of several conventionally tilled fields (D.R.A., unpublished data). As field size increases and the perimeter to area ratio decreases, we expected fewer P. pruinosa in the larger fields, and possibly fewer feral $B$. impatiens. Unfortunately, fields were selected before we knew which fields would be supplemented with A. mellifera hives. Consequently, supplementation and field size were confounded variables in our study; supplemented fields tended to be larger, with a mean size of $6.7 \mathrm{ha}$ and nonsupplemented fields tended to be smaller, with a mean size of 1.9 ha. Supplemented fields averaged over three times the area of nonsupplemented fields and the field perimeter to area ratio was greater for the smaller, nonsupplemented fields compared with larger, supplemented ones. This may help explain why there were significantly more $P$. pruinosa in nonsupplemented fields compared with supplemented fields, and field size may not have been a significant factor predicting $P$. pruinosa visits in the nonsupplemented fields if there was not a sufficient range in field sizes to detect an effect of field size. In contrast, $B$. impatiens was affected by field size in the nonsupplemented fields. As field size increased, the mean number of B. impatiens visits per flower decreased. Work by Artz and Nault (2011) showed that pumpkin fruit weight and seed set resulting from visits by $B$. impatiens were significantly higher than A. mellifera on a per-visit basis. Therefore, supplementation of larger fields with $B$. impatiens may be useful.

When all three bee species were combined in an analysis, the mean number of flowers per field had a significant negative effect on the mean number of bee visits per flower, suggesting that there may a dilution response. As the number of flowers in the field increased, the number of bee visits per flower decreased. Analyzing the three species independently showed that $B$. impatiens was the most sensitive to flower density, but the effect was only significant in nonsupplemented fields. In fields that were not supplemented with A. mellifera, there was a significant negative relationship between the mean number of flowers and the mean number of $B$. impatiens visits per flower.

Recent declines in A. mellifera populations have stressed the need to examine the contribution of alternative pollinators to pollination services of plants in both natural and managed systems. Several agriculturally-important crop plants, like cucurbits, require insect pollinators for some or all of their reproduction, so identifying common native bee species and ways to enhance and promote their populations may be crucial for mitigating the effects of declining A. mellifera populations and the pollination services they provide. Furthermore, determining which bee species are most effective in a particular crop will provide insights into implementing on-farm and habitat management practices that will benefit the pollinators and improve and sustain crop yields. Based on results presented in this study and those reported by Artz and Nault (2011), declining $A$. mellifera populations may increase the relative importance of $B$. impatiens in pollinating pumpkins in New York. 


\section{Acknowledgments}

We thank E. Abbott, M. Bekauri, C. Boutard-Hunt, L. Duque, B. English-Loeb, M. L. Hessney, M. Lopez-Uribe, J. Petzoldt, K. Reiners, H. Schoonover, and B. Viertel for field assistance. We are grateful to all the growers who allowed us to survey bees on their fields. We thank J. Ascher, B. Danforth, and E. R. Hoebeke for help with identifying insects and R. Kaczorowski with assistance with nectar sampling techniques. We thank S. Despa, S. Sadigov, and F. Vermeylen who provided helpful advice on the statistical methods. We thank J. Petersen for helpful comments on the manuscript. This research was funded by Federal Formula Funds and Federal Hatch Funds.

\section{References Cited}

Abbott, K. R. 2006. Bumblebees avoid flowers containing evidence of past predation events. Can. J. Zool. 84: 12401247.

Aizen, M. A., L. A. Garibaldi, S. A. Cunningham, and A. M. Klein. 2009. How much does agriculture depend on pollinators? Lessons from long-term trends in crop production. Ann. Bot. 103: 1579-1588.

Andersen, J. F., and R. L. Metcalf. 1987. Factors influencing distribution of Diabrotica spp. in blossoms of cultivated Cucurbita spp. J. Chem. Ecol. 13: 681-699.

Artz, D. R., and B. A. Nault. 2011. Performance of Apis mellifera, Bombus impatiens and Peponapis pruinosa (Hymenoptera: Apidae) as pollinators of pumpkin. J. Econ. Entomol. 104: 1153-1161.

Artz, D. R., C. A. Villagra, and R. A. Raguso. 2010. Spatiotemporal variation in the reproductive ecology of two parapatric subspecies of Oenothera cespitosa (Onagraceae). Am. J. Bot. 97: 1-13.

Ashworth, L., and L. Galetto. 2002. Differential nectar production between male and female flowers in a wild cucurbit: Cucurbita maxima ssp. andreana (Cucurbitaceae). Can. J. Bot. 80: 1203-1208.

Beekman, M., and F.L.W. Ratnieks. 2000. Long-range foraging by the honey-bee, Apis mellifera L. Funct. Ecol. 14: $490-496$.

Brunet, J. 2009. Pollinators of the Rocky Mountain columbine: temporal variation, functional groups and associations with floral traits. Ann. Bot. 103: 1567-1578.

Cane, J. H. 2008. Pollinating bees crucial to farming wildflower seed for U.S. habitat restoration. In R. R. James and T. Pitts-Singer (eds.), Bees in agricultural ecosystems, Oxford University Press, New York.

Cane, J. H., and J. A. Payne. 1993. Regional, annual and seasonal variation in pollinator guilds: intrinsic traits of bees (Hymenoptera: Apoidea) underlie their patterns of abundance at Vaccinium ashei (Ericaceae). Ann. Entomol. Soc. Am. 86: 577-588.

Canto, A., C. M. Herrera, M. Medrano, R. Pérez, and I. Garcia. 2008. Pollinator foraging modifies nectar sugar composition in Helleborus foetidus (Ranunculaceae): an experimental test. Am. J. Bot. 95: 315-320.

Corbet, S. A., N. M. Saville, M. Fussell, O. E. Prys-Jones, and D. M. Unwin. 1995. The competition box: a graphical aid to forecasting pollinator performance. J. Appl. Ecol. 32: $707-719$.

Costich, D. E., and T. R. Meagher. 2001. Impacts of floral gender and whole-plant gender on floral evolution in Ecballium elaterium (Cucurbitaceae). Biol. J. Linn. Soc. 74: 475- 487 .
Decker, D. S. 1988. Origin(s), evolution, and systematics of Cucurbita pepo (Cucurbitaceae). Econ. Bot. 42: 4-15.

Delaplane, K. S., and D. F. Mayer. 2000. Crop pollination by bees. CABI Publishing, Oxon, United Kingdom.

Dukas, R. 2001. Effects of perceived danger on flower choice by bees. Ecol. Lett. 4: 327-333.

Eickwort, G. C., and H. S. Ginsberg. 1980. Foraging and mating behavior in Apoidea. Annu. Rev. Entomol. 25: 421- 446 .

Elliott, S. E., and R. E. Irwin. 2009. Effects of flowering plant density on pollinator visitation, pollen receipt, and seed production in Delphinium barbeyi (Ranunculaceae). Am. J. Bot. 96: 912-919.

Free, J. B. 1993. Insect pollination of crops, 2nd ed. Academic, London.

Fronk, W. D., and J. A. Slater. 1956. Insect fauna of cucurbit flowers. J. Kans. Entomol. Soc. 29: 141-145.

Galen, C. 1989. Measuring pollinator-mediated selection on morphometric floral traits: bumblebees and the alpine sky pilot, Polemonium viscosum. Evolution 43: 882-890.

Galen, C., and M.E.A. Newport. 1988. Pollination quality, seed set, and flower traits in Polemonium viscosum: complementary effects of variation in flower scent and size. Am. J. Bot. 75: 900-905.

Gallai, N., J-M. Salles, J. Settele, and B. E. Vaissière. 2009. Economic valuation of the vulnerability of world agriculture confronted with pollinator decline. Ecol. Econ. 68: $810-821$.

Gomez, J. M., and R. Zamora. 1999. Generalization vs. specialization in the pollination system of Hormathophylla spinosa (Cruciferae). Ecology 80: 796-805.

Goulson, D., and K. R. Sparrow. 2009. Evidence for competition between honeybees and bumblebees; evidence on bumblebee worker size. J. Insect Conserv. 13: $177-181$.

Greenleaf, S. S., and C. Kremen. 2006. Wild bees enhance honey bees' pollination of hybrid sunflower. Proc. Natl. Acad. Sci. USA 103: 13890-13895.

Harder, L. D., and W. G. Wilson. 1997. Theoretical perspectives on pollination. Acta Hortic. 437: 83-101.

Heinrich, B. 2004. Bumblebee economics. Harvard University Press, Cambridge, Massachusetts.

Herrera, C. M. 1987. Components of pollinator "quality": comparative analysis of a diverse insect assemblage. Oikos 50: $79-90$.

Hladun, K. R., and L. S. Adler. 2009. Influence of leaf herbivory, root herbivory, and pollination on plant performance in Cucurbita moschata. Ecol. Entomol. 34: $144-152$.

Hodgins, K. A., and S.C.H. Barrett. 2008. Natural selection on floral traits through male and female function in wild populations of the heterostylous daffodil Narcissus triandrus. Evolution 62: 1751-1763.

Hurd, P. D., E. G. Linsley, and A. E. Michelbacher. 1974. Ecology of the squash and gourd bee, Peponapis pruinosa, on cultivated cucurbits in California (Hymenoptera: Apoidea). Smithson. Contrib. Zool. no. 168: 1-17.

Irwin, R. E., and A. K. Brody. 1999. Nectar-robbing bumble bees reduce the fitness of Ipomopsis aggregata (Polemoniaceae). Ecology 80: 1703-1712.

James, R. R., and T. L. Pitts-Singer. 2008. Bee pollination in agricultural ecosystems. Oxford University Press, New York.

Julier, H. E., and T. H. Roulston. 2009. Wild bee abundance and pollination service in cultivated pumpkins: farm management, nesting behavior and landscape effects. J. Econ. Entomol. 102: 563-573. 
Kaczorowski, R. L., T. E. Juenger, and T. P. Holtsford. 2008. Heritability and correlation structure of nectar and floral morphology traits in Nicotiana alata. Evolution 62: 1738 1750.

Kallimanis, A. S., T. Petanidou, J. Tzanopoulos, J. D. Pantis, and S. P. Sgardelis. 2009. Do plant-pollinator interaction networks result from stochastic processes? Ecol. Modell. 220: 684-693.

Kearns, C. A., and D. W. Inouye. 1993. Techniques for pollination biologists. University Press of Colorado, Niwot, Colorado

Keasar, T., E. Rashkovich, D. Cohen, and A. Shmida. 2002. Bees in two-armed bandit situations: foraging choices and possible decision mechanisms. Behav. Ecol. 13: 757-765.

Kevan, P. G., N. A. Mohr, M. D. Offer, and J. R. Kemp. 1988. The squash and gourd bee, Peponapis pruinosa (Hymenoptera, Anthophoridae) in Ontario, Canada. Proc. Entomol. Soc. Ont. 119: 9-15.

Klein, A.-M., B. E. Vaissiere, J. H. Cane, I. Steffan-Dewenter, S. A. Cunningham, C. Kremen, and T. Tscharntke. 2007. Importance of pollinators in changing landscapes for world crops. Proc. R. Soc. Biol. Sci. 274: 303-313.

Klinkhamer, P.G.L., and T. J. de Jong. 1990. Effects of plant size, plant density and sex differential nectar reward on pollinator visitation in the protandrous Echium vulgare. Oikos 57: 399-405.

Kremen, C., R. L. Bugg, N. Nicola, S. A. Smith, R. W. Thorp, and N. M. Williams. 2002a. Native bees, native plants and crop pollination in California. Fremontia 30: 41-49.

Kremen, C., N. M. Williams, and R. W. Thorp. 2002b. Crop pollination from native bees at risk from agricultural intensification. Proc. Natl. Acad. Sci. USA 99: 16812-16818.

Kremen, C., N. M. Williams, M. A. Aizen, B. Gemmill-Herren, G. LeBuhn, R. Minckley, L. Packer, S. G. Potts, T. Roulston, I. Steffan-Dewenter, et al. 2007. Pollination and other ecosystem services produced by mobile organisms: a conceptual framework for the effects of land-use change. Ecol. Lett. 10: 299-314

Losey, J. E., and M. Vaughan. 2006. The economic value of ecological services provided by insects. Bioscience 56 : 311-323.

Majetic, C. J., R. A. Raguso, and T. Ashman. 2009. The sweet smell of success: floral scent affects pollinator attraction and seed fitness in Hesperis matronalis. Funct. Ecol. 23: $480-487$

Meléndez-Ackerman, E., and D. R. Campbell. 1998. Adaptive significance of flower color and inter-trait correlations in an Ipomopsis hybrid zone. Evolution 52: 12931303.

Metcalf, R. L., and R. L. Lampman. 1989. The chemical ecology of diabroticites and Cucurbitaceae. Experientia 45: $240-247$.

Metcalf, R. L., R. L. Lampman, and L. Deem-Dickson. 1995. Indole as an olfactory synergist for volatile kairomones for diabroticite beetles. J. Chem. Ecol. 21: 1149-1162.

Mitchell, R. J. 2004. Heritability of nectar traits: why do we know so little? Ecology 85: 1527-1533.

Morse, R. A., and N. W. Calderone. 2000. The value of honey bees as pollinators of U.S. crops in 2000. Bee Cult. 128: $1-15$.

[NRC] National Research Council. 2006. Status of pollinators in North America. Natl. Acad. Sci. Press, Washington, DC.

Nee, M. 1990. The domestication of Cucurbita (Cucurbitaceae). Econ. Bot. 44 (No. 3 Suppl.): 56-68.
Ne'eman, G., O. Shavit, L. Shaltiel, and A. Shmida. 2006. Foraging by male and female bees with implications for pollination. J. Insect Behav. 19: 383-401.

Nepi, M., and E. Pacini. 1993. Pollination, pollen viability, and pistil receptivity in Cucurbita pepo. Ann. Bot. 72 527-536.

Paini, D. R. 2004. Impact of the introduced honey bee (Apis mellifera) (Hymenoptera: Apidae) on native bees: a review. Austral. Ecol. 29: 399-407.

Petanidou, T., A. S. Kallimanis, J. Tzanopoulos, S. P. Sgardelis, and J. D. Pantis. 2008. Long-term observation of a pollination network: fluctuation in species and interactions, relative invariance of network structure and implications for estimates of specialization. Ecol. Lett. 11: 564-575.

Salzmann, C. C., S. Cozzolino, and F. P. Schiestl. 2007. Floral scent in food-deceptive orchids: species specificity and sources of variability. Plant Biol. 9: 720-729.

SAS Institute. 2007. SAS user's guide, version 9.2. SAS Institute, Cary, NC.

Seeley, T. D. 1995. The wisdom of the hive. Harvard University Press, Cambridge, Massachusetts.

Shavit, O., A. Dafni, and G. Ne'eman. 2009. Competition between honeybees (Apis mellifera) and native solitary bees in the Mediterranean region of Israel-Implications for conservation. Isr. J. Plant Sci. 57: 171-183.

Shuler, R. E., T. H. Roulston, and G. E. Farris. 2005. Farming practices influence wild pollinator populations on squash and pumpkin. J. Econ. Entomol. 98: 790-795.

SPSS. 2005. SPSS for Windows, version 14.0. SPSS, Chicago, IL.

Steffan-Dewenter, I., and A. Kuhn. 2003. Honeybee foraging in differentially structured landscapes. Proc. R. Soc. B. 270: $569-575$.

Tepedino, V. J. 1981. The pollination efficiency of the squash bee (Peponapis pruinosa) and the honey bee (Apis mellifera) on summer squash (Cucurbita pepo). J. Kans. Entomol. Soc. 54: 359-377.

Thomson, D. 2004. Competitive interactions between the invasive European honey bee and native bumble bees. Ecology 85: 458-470.

Thomson, J. D. 1980. Skewed flowering distributions and pollinator attraction. Ecology 61: 572-579.

U.S. Department of Agriculture, National Agricultural Statistical Service Quick Stats, New York. 2008. (http:// www.nass.usda.gov/QuickStats/Create Federal Indv.jsp).

vanEngelsdorp, D., J. Hayes, R. M. Underwood, D. Caron, and J. Pettis. 2011. A survey of managed honey bee colony losses in the USA, fall 2009 to winter 2010. J. Apic. Res. 50: 1-10.

Visscher, P. K., and T. D. Seeley. 1982. Foraging strategy of honeybee colonies in a temperate deciduous forest. Ecology 63: $1790-1801$.

Whitaker, T. W. 1931. Sex ratio and sex expression in the cultivated cucurbits. Am. J. Bot. 18: 359-366.

Whitaker, T. W. 1981. Archeological cucurbits. Econ. Bot. 35: $460-466$.

Whitaker, T. W., and J. C. Bird. 1949. Identification and significance of the cucurbit materials from Huaca Prieta, Peru. Am. Mus. Novit. 1426: 1-15.

Whitaker, T. W., and G. N. Davis. 1962. Cucurbits: botany, cultivation and utilization. Interscience Publ., Inc., New York

Willis, D. S., and P. G. Kevan. 1995. Foraging dynamics of Peponapis pruinosa (Hymenoptera: Anthophoridae) on pumpkin (Cucurbita pepo) in southern Ontario. Can. Entomol. 127: 167-175. 
Winfree, R., N. M. Williams, J. Dushoff, and C. Kremen. 2007. Native bees provide insurance against ongoing honey bee losses. Ecol. Lett. 10: 1105-1113.

Wyatt, R., S. B. Broyles, and G. S. Derda. 1992. Environmental influences on nectar production in milkweeds (Asclepias syriaca and A. exaltata). Am. J. Bot. 79: 636642 .
Yokoi, T., and K. Fujisaki. 2011. To forage or not: responses of bees to the presence of other bees on flowers. Ann. Entomol. Soc. Am. 104: 353-357.

Zar, J. H. 1999. Biostatistical Analysis, 4th ed. Prentice Hall, Upper Saddle River, NJ.

Received 27 August 2010; accepted 24 June 2011. 